\title{
Nanostructured Tin-based Alloys Composites using Deep Eutectic Solvents as Electrolytes
}

\author{
Ana T. S. C. Brandão ${ }^{1}$, Renata Costa ${ }^{2}$, A. Fernando Silva ${ }^{3}$, \\ Carlos M. Pereira ${ }^{4}$ \\ ${ }^{1}$ CIQUP - Chemistry Research Center, Faculty of Sciences, University of Porto, Rua do Campo \\ Alegre 1021, 4169-007 Porto, Portugal; Department of Chemistry and Biochemistry, Faculty of \\ Sciences, University of Porto, Rua do Campo Alegre, 4169-007 Porto, Portugal \\ (atscbrandao@gmail.com) ORCID 0000-0003-3291-7713; 2CIQUP - Chemistry Research \\ Center, Faculty of Sciences, University of Porto, Rua do Campo Alegre 1021, 4169-007 Porto, \\ Portugal; Department of Chemistry and Biochemistry, Faculty of Sciences, University of Porto, \\ Rua do Campo Alegre, 4169-007 Porto, Portugal (renata.costa@fc.up.pt) ORCID 0000-0002- \\ 3259-5729; ${ }^{3} \mathrm{CIQUP}$ - Chemistry Research Center, Faculty of Sciences, University of Porto, Rua \\ do Campo Alegre 1021, 4169-007 Porto, Portugal; Department of Chemistry and Biochemistry, \\ Faculty of Sciences, University of Porto, Rua do Campo Alegre, 4169-007 Porto, Portugal \\ (afssilva@fc.up.pt) ORCID 0000-0002-6332-5182; ${ }^{4}$ CIQUP - Chemistry Research Center, \\ Faculty of Sciences, University of Porto, Rua do Campo Alegre 1021, 4169-007 Porto, Portugal; \\ Department of Chemistry and Biochemistry, Faculty of Sciences, University of Porto, Rua do \\ Campo Alegre, 4169-007 Porto, Portugal (cmpereir@fc.up.pt) ORCID 0000-0002-8392-9581
}

\begin{abstract}
Metal and alloys electrodeposition from aqueous electrolytes is restricted due to the narrow electrochemical window and hydrogen evolution. To overcome these disadvantages, over the past years, ionic liquids (ILS) and deep eutectic solvents (DES) based on choline chloride have been successfully applied for the electrodeposition of different metals.

Tin (Sn) layers applied to automotive or decorative plating are thought of as ecological alternatives to exchange lead and nickel/chromium coatings. Over the past few years, the attention drawn by metallic alloys and composites, namely Sn alloys (nickel, indium, copper, zinc...) and Sn-carbon materials composites, has increased due to the possibility of applying these materials as anodes for lithium-ion batteries.

This review will highlight the leading research regarding the electrodeposition of Sn and several alloys and carbon composites, emphasizing the morphological changes of the alloy combinations using DESs as electrolytes.
\end{abstract}

Author Keywords. Tin, Tin Alloys, Deep Eutectic Solvents, Ionic Liquid, Electrodeposition, Lithium-ion Battery.

Type: Review Article

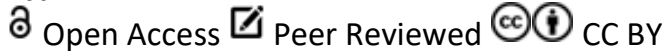

\section{Introduction}

The electrodeposition of metals and metallic alloys has been used for extensive range of applications, such as electroplating (Zhang and Hoshino 2014), electrowinning (Schlesinger et al. 2011b) and electrorefining (Schlesinger et al. 2011a). The electrodeposition technique is used in various domestic components to technological devices to improve the appearance and also to protect against corrosion (Sobha Jayakrishnan 2012).

Metals and alloys electrodeposition process relies on the metal ions reduction from the electrolyte solutions on the top of the surface to be coated (Tarditi, Bosko, and Cornaglia 2017). Figure 1 presents the principle behind the electroplating process. An electrodeposition cell consists of an anode (positive charge), a cathode (negative charge), an electrolytic bath, 
and a current/voltage source (Tarditi, Bosko, and Cornaglia 2017). Reduction and oxidation reactions occur at the cathode and anode, respectively, where the cathode is the conducting substrate on which the electrodeposition occurs, and the anode can be either soluble or inert. The overall reactions (Tarditi, Bosko, and Cornaglia 2017) taking place during electrolysis can be represented as: at the cathode $\left(\mathrm{M}^{\mathrm{Z}+}(\mathrm{aq})+\mathrm{ne}^{-} \rightarrow \mathrm{M}(\mathrm{m})\right.$, at the soluble anode $\left(\mathrm{M}^{\prime}(\mathrm{m}) \rightarrow\right.$ $\left.\mathrm{M}^{\prime 2+}(\mathrm{aq})+n e^{-}\right)$, and at the insoluble anode $\left(\mathrm{H}_{2} \mathrm{O}(\mathrm{l}) \rightarrow 2 \mathrm{H}^{+}(\mathrm{aq})+1 / 2 \mathrm{O}_{2}(\mathrm{~g})+2 \mathrm{e}^{-}\right)$, where $\mathrm{M}$ and $\mathrm{M}^{\prime}$ can be the same or different materials.

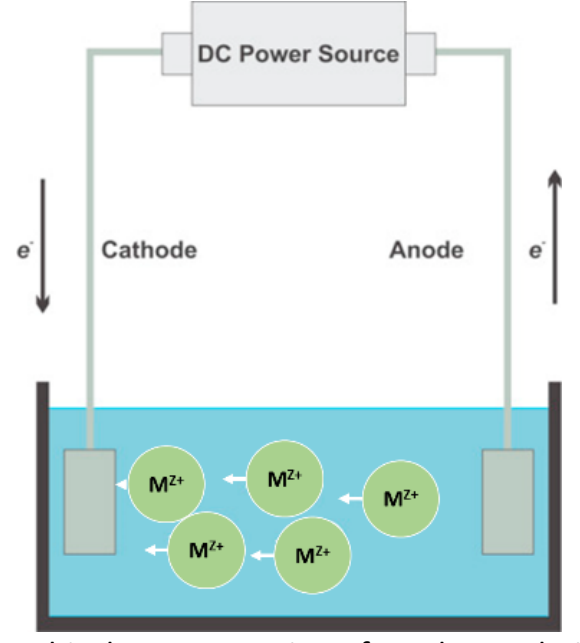

Figure 1: Graphical representation of an electroplating process

(Reproduced from Tarditi, Bosko, and Cornaglia (2017), with permission from Elsevier)

The electrodeposition method applied by the industrial sector is mainly based on aqueous systems as a result of the high solubility of electrolytes and metal salts present in water, which can lead to solutions with high conductivity (Smith, Abbott, and Ryder 2014). However, water presents a narrow potential window, making it not ideal for the deposition of metals with low current efficiencies. To overcome this problem, ionic liquids (ILS) are drawing much attention as an alternative for aqueous solutions in many electrochemical processes. This is mainly due to the wide potential window, high ionic conductivity and thermal stability, alongside low vapor pressure (Endres, Abbott, and MacFarlane 2008).

\section{Electrolyte - Which One Suits Best for Electrodeposition?}

Ionic liquids (ILs) were firstly presented by Habboush and Osteryoung (1984) for the replacement of aqueous baths, reducing the effect caused by hydrogen evolution. The main difference between these two electrolytes is their internal composition. ILs are entirely composed of ions, making some of them very viscous at room temperature, not being very practical to use. Also, ILs present high costs and are very susceptible to the presence of water (López-León, Ortega-Borges, and Brisard 2013).

There has been an increase in research about ILs throughout the years due to the necessity to improve the performances of the ionic solvents and developing new technologies. Up to now, there has been a continuous increase in studies about this matter, with almost 5000 new research publications each year.

More recently, Abbott et al. (2007a) introduced an alternative to ILs for metal electrodeposition, known as deep eutectic solvents (DESs). The first study regarding DESs was presented by the same author (Abbott et al. 2001), in which different quaternary ammonium salts were heated with zinc chloride, and the freezing points of the obtained liquids were measured. DESs are made through the complexation of a quaternary ammonium salt with a 
metal salt or with a hydrogen bond donor (HBD). The most common quaternary ammonium salt-based DES are those with amides, glycols, or carboxylic acids as HBDs (Abbott et al. 2001). DESs are considered as a new class of ILs because they present similar properties to ILS (Khandelwal, Tailor, and Kumar 2016; Lee and Row 2016), showing potential for the electrodeposition of metals and alloys (Abbott et al. 2007b; Abbott et al. 2008; Abbott et al. 2015; Anicai, Florea, and Visan 2011; Endres, Abbott, and MacFarlane 2008). The main difference between ILs and DESs is that the reduced melting points in DESs are achieved by the addition of HBDs, instead of changing the structure of the ions, in the case of the ILs (Chen et al. 2017). Figure 2 presents some examples of halide salts and HBDs.

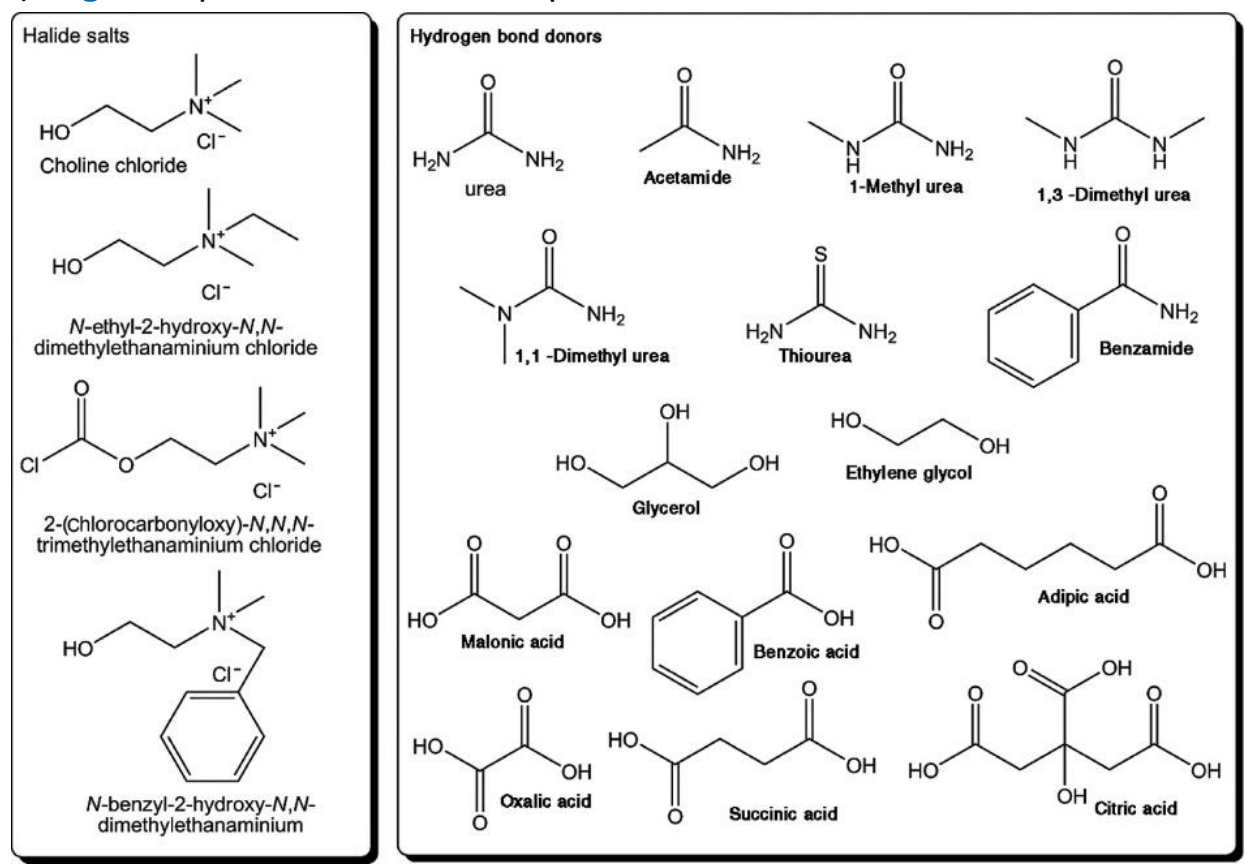

Figure 2: Structures of halide salts and HBDs used for DES formation

(Smith, Abbott, and Ryder (2014) - Open Access Copyright @ 2014 American Chemical Society)

The main focus in this review will be given to the mixtures of choline chloride salt $(\mathrm{ChCl})$ with ethylene glycol, malonic acid, and urea as HBDs for Sn and Sn-alloys electrodeposition.

\section{Tin Electrodeposition}

Tin coatings have been recognized as surface protectors from air oxidation (Walsh and Low $2016 b)$. The brightness of tin coatings also provides decorative finishes, appealing to the eye and is one of the few metals that are suitable for contact with food while cooking. Tin electrodeposition presents a long history, and several authors dedicated their attention to it (Gabe 2014; Jordan 1995; Walsh and Low 2016b).

Albeit the continuous increase in concern about health and environment tin is considered as an ecological alternative to replacing lead or nickel-chromium coatings (Han, Liu, and Ivey 2009; Jaén et al. 1991; Jellesen and Møller 2005). The melting point of tin is $223^{\circ} \mathrm{C}$, not making it easy to be used in its pure state (Smith, Abbott, and Ryder 2014). Combining Sn with other metals (e.g., nickel), forming alloys, makes them suitable for different applications, from surgical instruments, printed circuits boards, to electrical connectors, representing a substitute to chromium due to their excellent anticorrosive properties.

Several research groups have been working with Sn alloys. This chapter will be dedicated to present the main results, published so far, regarding the electrodeposition of different Snalloys (nickel (Ni), indium (In), copper (Co), and zinc(Zn)) and Sn-carbon composites in DESs. 


\subsection{Sn and Sn alloys electrodeposition in DESs}

This subsection is going to be focused on the electrodeposition of Sn alloys in DESs with electrochemical and morphological characterization. It will be mentioned the latest research regarding this matter, and with some alloys being addressed.

The alloy electrodeposition can be a very complicated process. According to several authors (Endres, Abbott, and MacFarlane 2008; Smith, Abbott, and Ryder 2014; Walsh and Low 2016b), alloy coatings require a potential that is considered negative regarding the reduction potential for the most cathodic metals. Though the fact that the concept looks simple, it is moderately challenging to control the alloy composition during the electrodeposition process. This is most probably due to the significant difference in the redox potentials of the two metal ions or due to the differential deposition kinetics of the two metals (Endres, Abbott, and MacFarlane 2008).

\subsubsection{Sn-Ni alloy electrodeposition}

The electrodeposition of Sn-Ni alloy was studied in different research papers using different DESs (Abbott et al. 2015; Anicai, Florea, and Visan 2011; Subramanian, Mohan, and Jayakrishnan 2007). Anicai et al. (2013) studied the electrodeposition and corrosion behavior of $\mathrm{Sn}$ and $\mathrm{Sn}-\mathrm{Ni}$ alloy coatings using choline chloride-based DES with ethylene glycol as HBD. The obtained $\mathrm{Sn}$ and $\mathrm{Sn}-\mathrm{Ni}$ alloy deposits present good adherence and uniformity, which is shown in Figure 3 through the SEM analysis, revealing distinct morphologies. Sn deposit present bigger nuclei, compared to $\mathrm{Sn}-\mathrm{Ni}$ alloy, indicating the significant change in morphology when more than one metal is being electrodeposited.

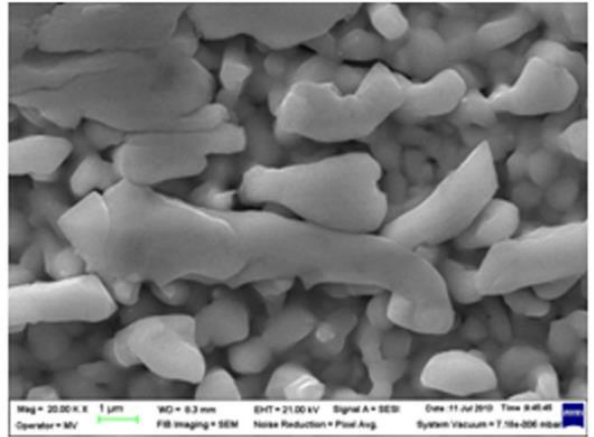

(a)

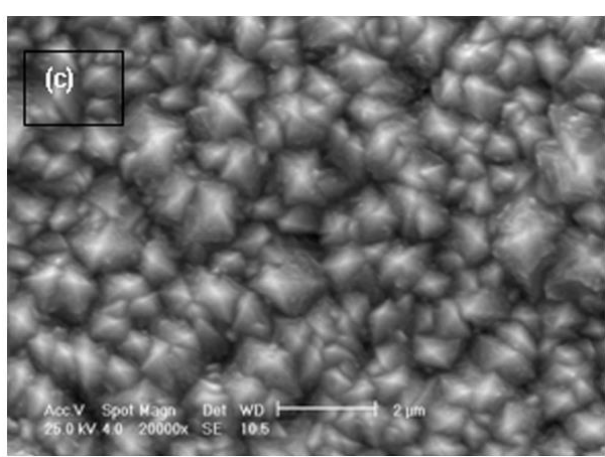

(b)

Figure 3: SEM images of $\mathrm{Sn}(\mathrm{a})$ and $\mathrm{Sn}-\mathrm{Ni}(\mathrm{b})$ regarding the same parameter using ethylene glycol as HBD (Reproduced from Anicai et al. (2013), with permission from Elsevier)

Different HBDs are a case of study regarding its effect on metal electrodeposition. In the same study, Anicai et al. (2013) presented some results regarding the use of malonic acid as HBD. The use of malonic acid as HBD showed good adherence, with an increase in the brightness of the coating and better corrosion performance.

Very recently, it was presented by Rosoiu et al. (2019) for the first time, Sn-Ni alloy electrodeposition by pulse current using ethylene glycol as HBD. In this work, it was compared the efficiency between pulse and direct current. It was established that the pulse current electrodeposition method leads to a diminution of the crystallite size, through the study by Xray diffraction (Figure 4), showing an enhancement in the mechanical properties when compared to the direct current method. 


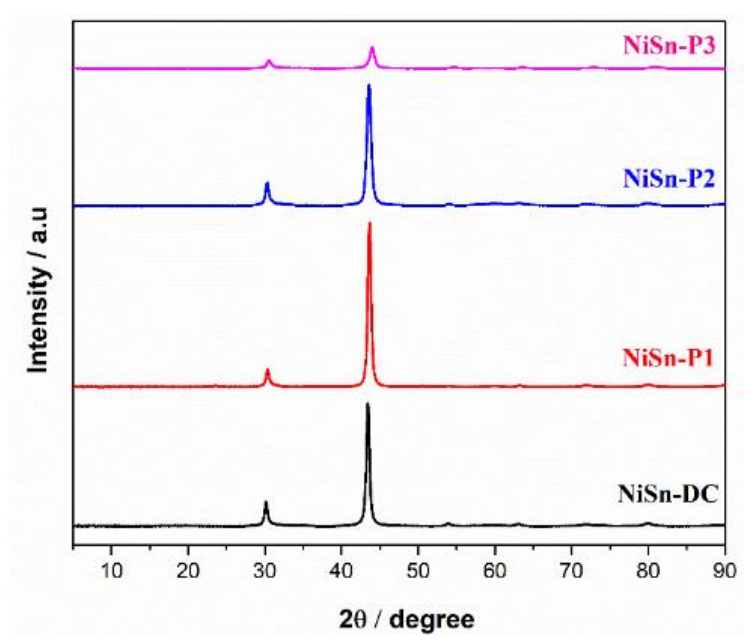

Figure 4: X-ray diffraction patterns of $\mathrm{Sn}-\mathrm{Ni}$ deposited on a copper substrate in direct current and pulsed current conditions (Rosoiu et al. (2019) - Open Access Copyright @ 2019 MDPI)

\subsubsection{Sn-In alloy electrodeposition}

Indium (In) is a metal with high technological importance, finding different applications in flat panel display devices, semiconductors, and solar cells (Schwarz-Schampera and Herzig 2002). The electrodeposition of In in aqueous electrolytes was studied, but the hydrogen gas evolution leads to shallow current intensity (Piercy and Hampson 1975; Walsh and Gabe 1979).

On the other hand, In electrodeposition was also investigated using non-aqueous electrolytes, namely ILs (Monnens et al. 2019; Zein El Abedin et al. 2007), DES (Alcanfor et al. 2017; Malaquias, Steichen, and Dale 2015) and molten salts (Carpenter and Verbrugge 1994) for electrowinning and formation of indium compounds.

It was proved that the addition of In could lead to the removal of whiskers growth in Sn electrodeposition, presenting a better behaviour compared to lead (Das Mahapatra et al. 2017; Das Mahapatra and Dutta 2018; Meinshausen et al. 2016). In addition to being used as lead-free, Sn-In alloys are also used as protective and wear-resistant coatings (Kim et al. 2018; Lai, Yang, and Yuan 2017).

Anicai et al. (2019) presented several experimental results regarding Sn-In alloy electrodeposition using DES as electrolyte with ethylene glycol as HBD. The In content found to increase with an increase of Sn: In molar concentration and increase in temperature. SEM analysis (Figure 5) of the alloy coatings presented irregular particles using direct current, while at pulse current, a more homogeneous and compact deposit was obtained. Pulse current also allowed to reach higher currents, and due to that, the amount of In was higher.

Corrosion tests were also performed. After 360 hours of continuous immersion in chloridecontaining aggressive medium, there was no change on the surface of the coatings. This shows that $\mathrm{Sn}$-In alloy presents good characteristics against corrosion, being excellent for different electronic applications, using DESs as an electrolyte. 

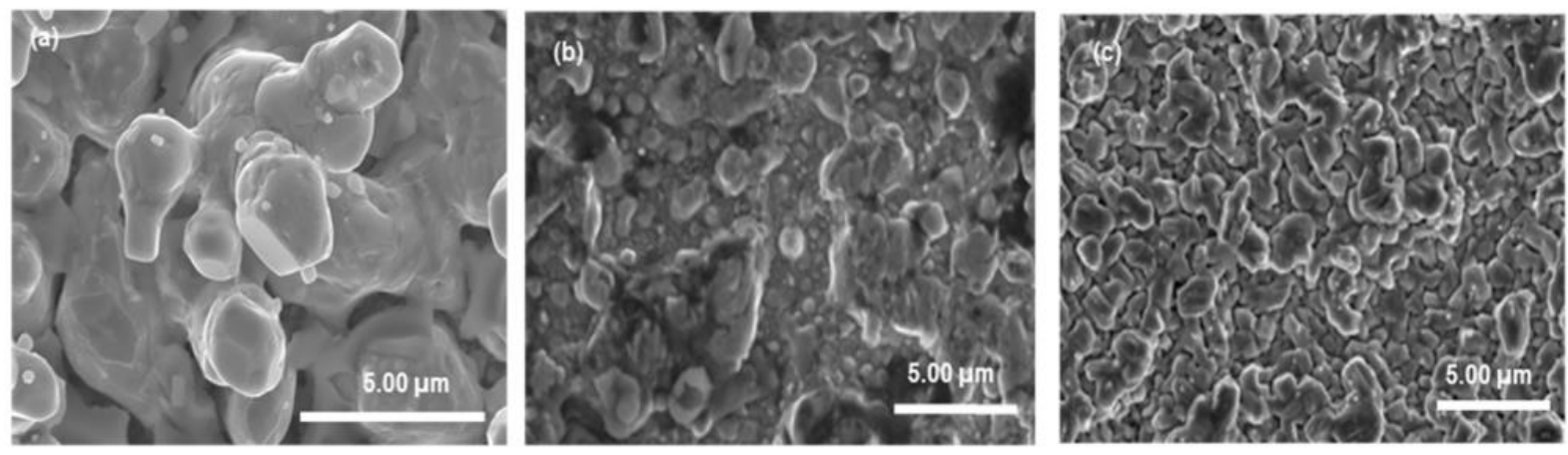

Figure 5: SEM analysis for Sn-In alloy from choline chloride-ethylene glycol electrolyte at $60^{\circ} \mathrm{C}((\mathrm{a}) 50 \mathrm{mM}$ of indium chloride $+50 \mathrm{mM}$ tin chloride, $2.5 \mathrm{~mA} \cdot \mathrm{cm}^{-2}$; (b) $100 \mathrm{mM}$ indium chloride $+30 \mathrm{mM}$ tin chloride, 2.5 $\mathrm{mA} \cdot \mathrm{cm}^{-2}$; (c) $100 \mathrm{mM}$ indium chloride $+30 \mathrm{mM}$ tin chloride, $10 \mathrm{~mA} \cdot \mathrm{cm}^{-2}$ (Anicai et al. (2019) - Open Access Copyright (C) 2019 MDPI)

\subsubsection{Sn-Cu alloy electrodeposition}

Abbott et al. (2016) studied the Sn-Cu alloy electrodeposition in DESs (ethylene glycol and urea as HBDs). This study was followed with the electrochemical quartz crystal microbalance (EQCM), showing the real-time monitoring of alloy composition. They were able to successfully deposit Sn-Cu alloys from DESs. EQCM analysis presented that the alloy composition is not homogeneous throughout the alloy film. This research paper was more focused on the study of the amount of metal present in each step of the electrodeposition, showing that some brighteners that work in aqueous solutions for copper electrodeposition are also useful in DESs.

\subsubsection{Sn-Zn alloy electrodeposition}

Abbott et al. (2007a) studied how DESs with two different HBDs can be used for the electrodeposition of Sn-Zn alloy. The HBD effect (ethylene glycol and urea) was evaluated.

This work allowed to show that $\mathrm{Zn}$ and $\mathrm{Sn}$ can be electrodeposited from both HBD individually and as an alloy. The research helped to understand that the composition and morphology of the alloy can be changed according to the DES used. That can be seen in Figure 6, where it is visible the change in morphology for $\mathrm{Sn}$ and alloy changing the HBD from the DESs.

The presence of alumina demonstrated that composite materials could improve the wear resistance of coatings, opening a new path to the use of these materials in various numbers of applications, from aviation to electronics.

Pereira et al. (2012) studied the morphological properties of Sn-Zn deposits using three different chelators (EDTA, HEDTA and Idranal VII), with choline chloride-ethylene glycol, 1,2Propylene glycol and urea as HBDs. The obtained results showed the Idranal VII produced uniform deposits with a high amount of $\mathrm{Zn}$. 


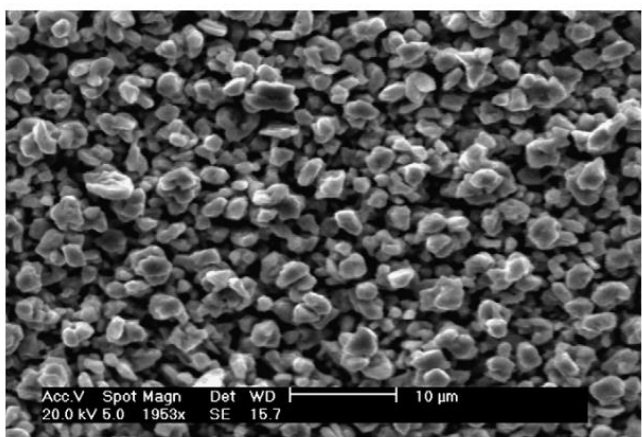

(a)

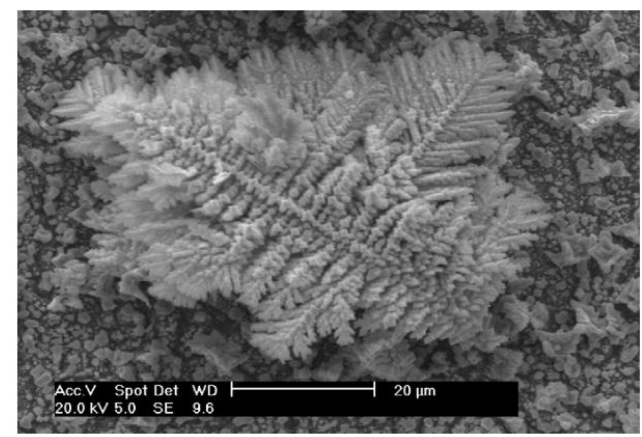

(b)

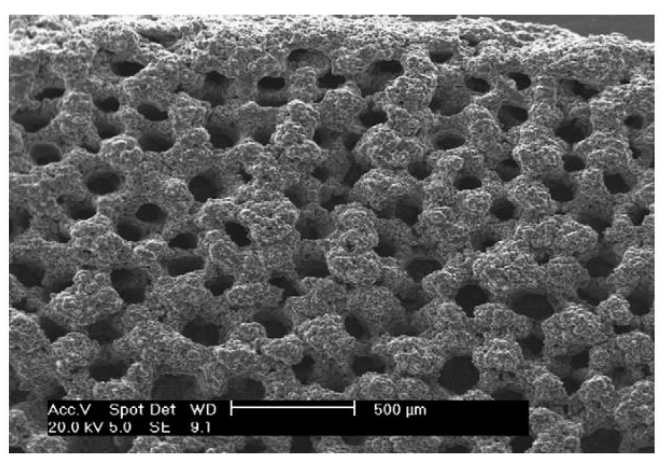

(c)

Figure 6: SEM analysis of Sn-Zn alloys electrodeposited films in choline chloride based DES electrolyte: (a) 0.5M zinc chloride/0.05 $\mathrm{M}$ tin chloride in DES with ethylene glycol as HBD at $10 \mathrm{~mA} / \mathrm{cm} 2$ for $1 \mathrm{~h}$; (b) $0.05 \mathrm{M}$ tin chloride in DES with urea as HBD at $10 \mathrm{~mA} / \mathrm{cm} 2$ for $30 \mathrm{~min}$; (c) $0.5 \mathrm{M}$ zinc chloride/0.05 $\mathrm{M}$ tin chloride in DES with urea as HBD + 3 wt\% alumina at $10 \mathrm{~mA} / \mathrm{cm} 2$ for $120 \mathrm{~min}$ (Reproduced from Abbott et al. (2007a), with permission from Elsevier)

\subsubsection{Sn-carbon composites electrodeposition}

The utilization of carbon materials in electrodeposition for the formation of metal composites are becoming of great interest (Brandão et al. 2019; Pereira et al. 2017; Tocoglu et al. 2014; Wang et al. 2001; Xu et al. 2013a; Xu et al. 2013b; Zhu et al. 2011).

Carbon nanotubes (CNTs) are made of graphene sheets rolled with a cylindrical shape, showing excellent properties such as high mechanical strength. Reinforcing metal deposits with CNTs or graphene presents high potential due to the extraordinary specific stiffness and strength of these carbon materials, representing a remarkable opportunity to develop new materials.

This is an area that presents an exponential growth regarding the research interest, with an increasing number of articles being published each year, according to the Science Direct website.

However, the incorporation of carbon materials, namely CNTs, into metal matrixes is still a challenge. Some research groups have presented successful results in the preparation of CNTs composites (Martis et al. 2011; Praveen and Venkatesha 2009; Rashad et al. 2015; Zhao et al. 2011).

Brandão et al. (2019) studied the incorporation of carbon materials (mostly multi-walled carbon nanotubes (MWCNTs) and oxidized MWCNTs in a metallic tin matrix using DES with ethylene glycol as HBD.

This research proved that it is possible to perform the electrodeposition of Sn and Sn-carbon materials composites using a eutectic mixture with ethylene glycol as HBD. The carbon 
materials present an excellent level of dispersion in the DES containing the Sn ions, allowing the incorporation of the carbon materials on the $\mathrm{Sn}$ metal matrix.

The SEM analysis, presented in Figure 7, proves the successful electrodeposition of Sn and Sncarbon materials.
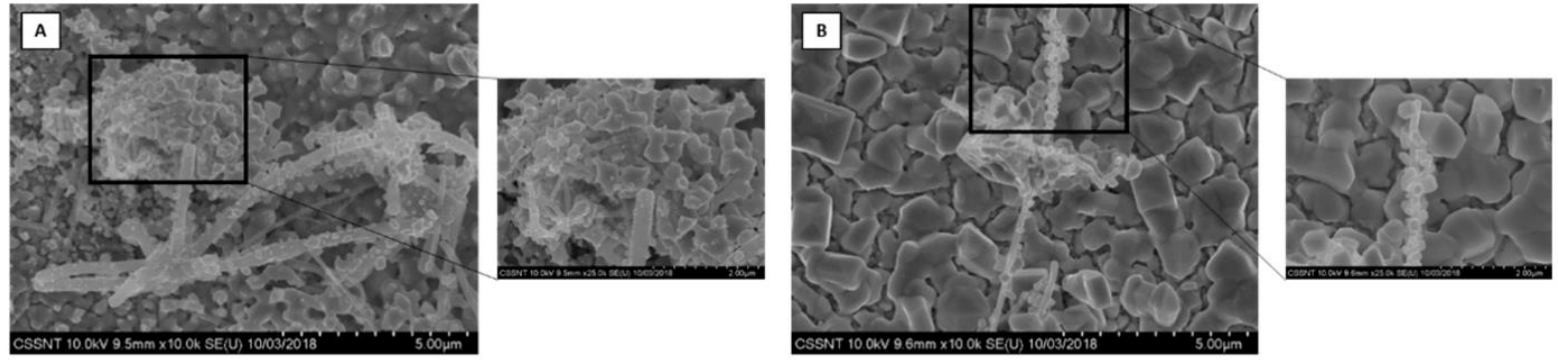

Figure 7: SEM analysis for $\mathrm{Sn}$ - oxidized MWCNTs composites at $75^{\circ} \mathrm{C}$ by chronoamperometry; (a) $0.01 \mathrm{M} \mathrm{Sn}+$ $0.5 \mathrm{~g} / \mathrm{L}$ oxidized MWCNTs (-1.25 V), (b) $0.01 \mathrm{M} \mathrm{Sn}$ (II)+ $0.5 \mathrm{~g} / \mathrm{L}$ oxidized MWCNTs (-1.50 V) (Brandão et al. (2019) - Open Access Copyright (C 2019 MDPI)

The incorporation of carbon materials on a metal matrix is of an extreme value since it can lead to the development of new metallic materials with increased properties for electronic and battery applications (Balach et al. 2018; Molenda and Molenda 2011; Shi et al. 2020).

\section{Future Regarding Tin Electrodeposition}

Sn electrodeposition on different substrates needs to be continuously studied to present better performance regarding the various applications. Several topics need to be considered in the future (Jordan 1995; Walsh and Low 2016a; Walsh and Low 2016b):

- Size increase of the surface to be deposited;

- Evolution of nucleation and growth morphology of the deposit, especially regarding the whisker growth;

- In-situ analysis through Raman spectroscopy to study the mechanisms of nucleation and growth of tin deposits.

\section{Application of Tin as Anode for Lithium-ion Batteries}

The development of high-performance rechargeable lithium batteries is of the highest importance for portable electronics and electric vehicles. This stimulates the continuous search for new and innovative electrode materials with huge capacities, long life, and higher rate capability (C. Liu et al. 2017).

Graphite is being considered as the most commonly used anode material in Li-ion batteries due to the low cost, accessibility, and durability (Shafiei and Alpas 2011). However, there has been a growing interest in using metals, intermetallic, and alloys as alternatives. Sn film anode presents a higher value of theoretical capacity (962 mAh. ${ }^{-1}$ ) compared to graphite (372 mAh.g ${ }^{-1}$ ) (Tarascon and Armand 2001).

Metals with foam structure have been used as current collectors to improve the electrochemical performance of Sn structure. Pores can accommodate the volumetric expansion but also allows fast reactions caused by its high surface area (Nam et al. 2012). Metal foam presents several advantages, such as easy preparation and thickness control, and large surface area (Shin and Liu 2005). Ni foam is a low-density permeable material where 75 to $95 \%$ of its volume consists of void spaces (Chen and Xue 2014).

The development of rechargeable lithium batteries is of great importance for portable electronic devices and electric vehicles (J. Liu et al. 2017). 
Tin anode presents a massive drawback as it undergoes significant volume changes during cycling, leading to mechanical stress and loss of electrical contact and lower cycle life (Shafiei and Alpas 2011). To overcome this problem, the use of alloy materials has been tested. Different tin alloys (Sn-Ni-P, Sn-Ni, and Sn-Co) have been considered (Cheng and Shi 2005; Mukaibo, Momma, and Osaka 2005; Naille et al. 2007; Xia, Lin, and Li 2008), with different electrochemical activities versus $\mathrm{Li} / \mathrm{Li}^{+}$, showing promising results with reducing volume expansion. Another approach is developing composite anode materials by mixing active elements with carbon materials, which was presented by several researchers (Arai and Fukuoka 2016; Choi and Yoon 2015; Dhanabalan et al. 2013; Lee et al. 2016; Polat et al. 2014; Tocoglu et al. 2014; Wang et al. 2009; Zuo et al. 2018), that may lead to an increase in conductivity and a higher control in the volume change.

Uysal et. al (2014) presented the application of Sn-Ni/MWCNTs nanocomposites as anodes for Li-ion batteries, in which the effect of the molar ratio of $\mathrm{Sn}$ : Ni was studied. Results presented that increasing the co-deposited $\mathrm{Ni}$ amount, a substantial impact on the electrochemical performance is observed.

Recently, Ahn et al. (2019) used electrochemical co-deposition to develop a silicon-based anode using tin as supporting materials, named $\mathrm{Sn} / \mathrm{Si} / \mathrm{O} / \mathrm{C}$ composite for application on lithium-ion batteries. Figure 8 presents the $\mathrm{Sn} / \mathrm{Si} / \mathrm{O} / \mathrm{C}$ composite using $\mathrm{SiCl}_{4}$ and $\mathrm{SnCl}_{2}$ as silicon and tin sources, with propylene carbonate as an electrolyte.

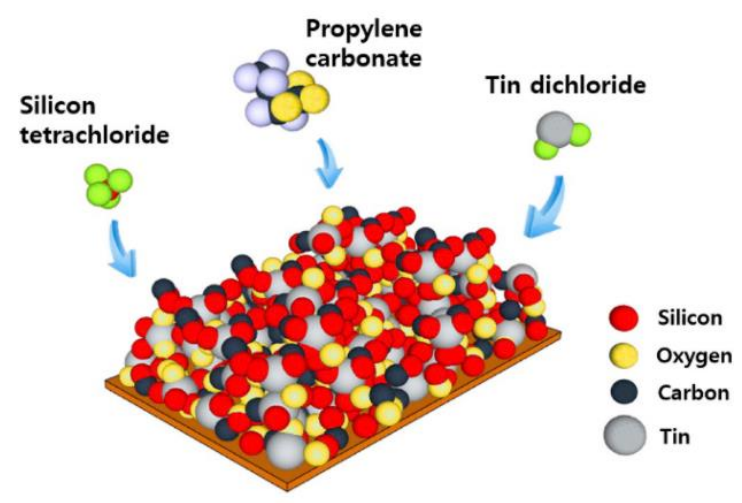

Figure 8: Representation of the electrodeposition process of $\mathrm{Sn} / \mathrm{Si} / \mathrm{O} / \mathrm{C}$ composite (Reproduced from Ahn et al. (2019), with permission from Elsevier)

Sn composite presents a whisker structure, which can act as an electron pathway, offering an improved electrochemical high rate performance, as presented in Figure 9. The electrochemical performance of $\mathrm{Sn} / \mathrm{Si} / \mathrm{O} / \mathrm{C}$ composite shows that this material has excellent potential as an anode for application in high energy density lithium-ion batteries.

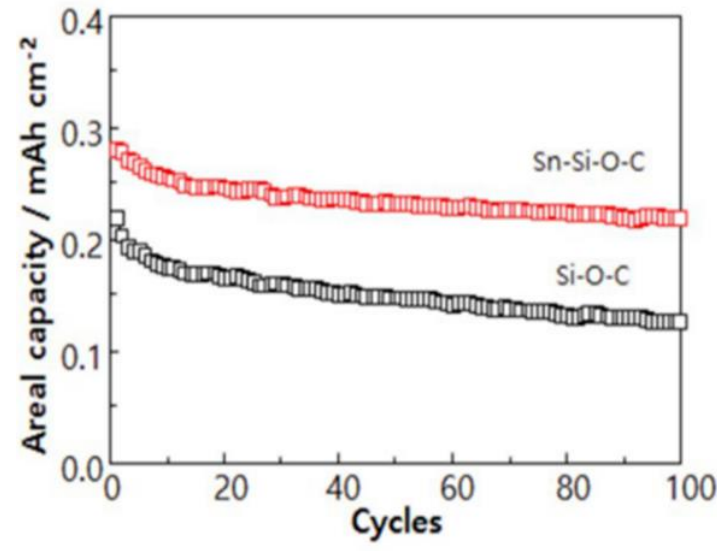

Figure 9: Capacity vs. cycle of $\mathrm{Sn} / \mathrm{Si} / \mathrm{O} / \mathrm{C}$ and $\mathrm{Si} / \mathrm{O} / \mathrm{C}$ composites with a voltage range between 1.2 and 0.01V (Reproduced from Ahn et al. (2019), with permission from Elsevier) 


\section{Conclusions}

This review has revealed that Sn alloy coatings deposited from DESs are becoming of great interest for different applications, namely as anodes for lithium-ion batteries.

DESs and ILs present many similarities regarding the physical properties, making DESs an excellent substitute for ILs. However, the difference regarding the chemical properties between these two liquids means that DESs can be used in different applications, compared to ILs.

It was reviewed some Sn alloys coatings and Sn-carbon composites developed in DESs and the morphological characteristics to understand the alloying effect as well as the presence of carbon materials on the Sn metallic matrix.

The electrodeposition of metal alloys and composites using DESs as electrolytes are becoming of great interest since it can be used as anodes for lithium-ion batteries. Even though DESs is still an immerging class for many applications, it presented some exciting results when applied for lithium-ion batteries.

It is necessary to continue the research regarding metal electrodeposition using DESs, since there is still lack of information regarding their characteristics. Only a small number of DESs formulation have been studied so far. With the increasing interest in using these type of electrolytes, there is a huge potential to expand the study to other type of salts and HBDs, and further increase the applications of these solvents.

\section{References}

Abbott, A. P., A. I. Alhaji, K. S. Ryder, M. Horne, and T. Rodopoulos. 2016. "Electrodeposition of copper-tin alloys using deep eutectic solvents". Transactions of the Institute of Metal Finishing 94, no. 2: 104-13. https://doi.org/10.1080/00202967.2016.1148442.

Abbott, A. P. P., K. El Ttaib, K. S. S. Ryder, and E.L. L. Smith. 2008. "Electrodeposition of nickel using eutectic based ionic liquids". Transactions of the Institute of Metal Finishing 86, no. 4 (july): 234-40. https://doi.org/10.1179/174591908X327581.

Abbott, A. P., A. Ballantyne, R. C. Harris, J. A. Juma, K. S. Ryder, and G. Forrest. 2015. "A comparative study of nickel electrodeposition using deep eutectic solvents and aqueous $\begin{array}{lllll}\text { solutions". } & \text { Electrochimica } & \text { Acta } & 176 & \text { (july): }\end{array}$ https://doi.org/10.1016/j.electacta.2015.07.051.

Abbott, A. P., G. Capper, K. J. McKenzie, and K. S. Ryder. 2007a. "Electrodeposition of zinc-tin alloys from deep eutectic solvents based on choline chloride". Journal of Electroanalytical Chemistry 599, no. 2 (january): 288-94. https://doi.org/10.1016/j.jelechem.2006.04.024.

Abbott, A. P., S. Nandhra, S. Postlethwaite, E. L. Smith, and K. S. Ryder. 2007b. "Electroless deposition of metallic silver from a choline chloride-based ionic liquid: A study using acoustic impedance spectroscopy, SEM and atomic force microscopy". Physical Chemistry Chemical Physics 9, no. 28: 3735-43. https://doi.org/10.1039/b703954a.

Abbott, A. P., G. Capper, D. L. Davies, H. L. Munro, R. K. Rasheed, and V. Tambyrajah. 2001. "Preparation of novel, moisture-stable, Lewis-acidic ionic liquids containing quaternary ammonium salts with functional side chains". Chemical Communications 1, no. 19: 201011. https://doi.org/10.1039/b106357j.

Ahn, S., T. Kadoya, H. Nara, T. Yokoshima, T. Momma, and T. Osaka. 2019. "Tin addition for mechanical and electronic improvement of electrodeposited $\mathrm{Si}-\mathrm{O}-\mathrm{C}$ composite anode for lithium-ion battery". Journal of Power Sources 437 (october): Article number 226858. https://doi.org/10.1016/j.jpowsour.2019.226858. 
Alcanfor, A. A. C., L. P. M. dos Santos, D. F. Dias, A. N. Correia, and P. de Lima-Neto. 2017. "Electrodeposition of indium on copper from deep eutectic solvents based on choline chloride and ethylene glycol". Electrochimica Acta 235 (may): 553-60. https://doi.org/10.1016/j.electacta.2017.03.082.

Anicai, L., A. Florea, and T. Visan. 2011. "Studies regarding the nickel electrodeposition from choline chloride based ionic liquids". In Applications of Ionic Liquids in Science and Technology, edited by S. Handy, 261-86. IntechOpen. https://doi.org/10.5772/23676.

Anicai, L., A. Petica, S. Costovici, C. Moise, O. Brincoveanu, and T. Visan. 2019. "Electrodeposition of Sn-In alloys involving deep eutectic solvents". Coatings 9, no. 12: Article number 800. https://doi.org/10.3390/coatings9120800.

Anicai, L., A. Petica, S. Costovici, P. Prioteasa, and T. Visan. 2013. "Electrodeposition of Sn and $\mathrm{NiSn}$ alloys coatings using choline chloride based ionic liquids - Evaluation of corrosion behavior". Electrochimica Acta 114 (december): 868-77. https://doi.org/10.1016/j.electacta.2013.08.043.

Arai, S., and R. Fukuoka. 2016. "A carbon nanotube-reinforced noble tin anode structure for lithium-ion batteries". Journal of Applied Electrochemistry 46, no. 3 (march): 331-38. https://doi.org/10.1007/s10800-016-0933-5.

Balach, J., J. Linnemann, T. Jaumann, and L. Giebeler. 2018. "Metal-based nanostructured materials for advanced lithium-sulfur batteries". Journal of Materials Chemistry A 6, no. 46: 23127-68. https://doi.org/10.1039/c8ta07220e.

Brandão, A. T. S. C., L. Anicai, O. A. Lazar, S. Rosoiu, A. Pantazi, R. Costa, M. Enachescu, C. M. Pereira, and A. F. Silva. 2019. "Electrodeposition of Sn and Sn composites with carbon materials using choline chloride-based ionic liquids". Coatings 9, no. 12: Article number 798. https://doi.org/10.3390/coatings9120798.

Carpenter, M. K., and M. W. Verbrugge. 1994. "Electrochemical codeposition of indium and antimony from a chloroindate molten salt". Journal of Materials Research 9, no. 10 (october): 2584-91. https://doi.org/10.1557/jmr.1994.2584.

Chen, K., and D. Xue. 2014. "Electrochemically stabilized porous nickel foam as current collector and counter electrode in alkaline electrolyte for supercapacitor". Journal of Nanoengineering and Nanomanufacturing 4, no. 1 (march): 50-55. https://doi.org/10.1166/jnan.2014.1168.

Chen, Z., M. Ludwig, G. G. Warr, and R. Atkin. 2017. "Effect of cation alkyl chain length on surface forces and physical properties in deep eutectic solvents". Journal of Colloid and Interface Science 494 (may): 373-79. https://doi.org/10.1016/j.jcis.2017.01.109.

Cheng, X.-Q., and P.-F. Shi. 2005. "Electroless Cu-plated $\mathrm{Ni}_{3} \mathrm{Sn}_{4}$ alloy used as anode material for lithium ion battery". Journal of Alloys and Compounds 391, no. 1-2 (april): 241-44. https://doi.org/10.1016/j.jallcom.2004.08.080.

Choi, H., and H. Yoon. 2015. "Nanostructured electrode materials for electrochemical capacitor applications". Nanomaterials 5, no. 2 (june): 906-36. https://doi.org/10.3390/nano5020906.

Das Mahapatra, S., and I. Dutta. 2018. "Co-electrodeposition of tin with $0.2-20 \%$ indium: Implications on tin whisker growth". Surface and Coatings Technology 337 (march): 47883. https://doi.org/10.1016/j.surfcoat.2018.01.061.

Das Mahapatra, S., B. S. Majumdar, I. Dutta, and S. Bhassyvasantha. 2017. "Eliminating whisker growth by indium addition in electroplated Sn on copper substrate". Journal of Electronic Materials 46, no. 7 (july): 4062-75. https://doi.org/10.1007/s11664-016-5177-y. 
Dhanabalan, A., X. Li, R. Agrawal, C. Chen, and C. Wang. 2013. "Fabrication and characterization of $\mathrm{SnO}_{2}$ /graphene composites as high capacity anodes for Li-ion batteries". Nanomaterials 3, no. 4 (november): 606-14. https://doi.org/10.3390/nano3040606.

Endres, F., A. P. Abbott, and D. R. MacFarlane, eds. 2008. Electrodeposition from ionic liquids. Wiley-VCH Verlag GmbH \& Co. KGaA. https://doi.org/10.1002/9783527682706.

Gabe, D. R. 2014. Principles of metal surface treatment and protection. Pergamon International Library of Science, Technology, Engineering and Social Studies: International Series on Materials Science and Technology, edited by D. W. Hopkins. 2nd ed. Pergamon.

Habboush, D. A., and R. A. Osteryoung. 1984. "Electrochemical studies of antimony(III) and antimony $(\mathrm{V})$ in molten mixtures of aluminum chloride and butylpyridinium chloride". Inorganic Chemistry 23, no. 12 (march): 1726-34. https://doi.org/10.1021/ic00180a018.

Han, C. F., Q. Liu, and D. G. Ivey. 2009. "Nucleation of Sn and Sn-Cu alloys on Pt during electrodeposition from Sn-citrate and Sn-Cu-citrate solutions". Electrochimica Acta 54, no. 12 (april): 3419-27. https://doi.org/10.1016/j.electacta.2008.12.064.

Jaén, J. A., M. L. Varsányi, H. Csontos, and A. Vértes. 1991. "The phase composition of tinnickel electrodeposited alloys". Hyperfine Interactions 66, no. 1-4 (november): 101-04. https://doi.org/10.1007/bf02395860.

Jellesen, M. S., and P. Møller. 2005. "The electrochemical deposition of tin-nickel alloys and the corrosion properties of the coating". Plating and Surface Finishing 92, no. 10 (october): 36-41.

Jordan, M. 1995. The electrodeposition of tin and its alloys. Leuze.

Khandelwal, S., Y. K. Tailor, and M. Kumar. 2016. "Deep eutectic solvents (DESs) as eco-friendly and sustainable solvent/catalyst systems in organic transformations". Journal of Molecular Liquids 215 (march): 345-86. https://doi.org/10.1016/j.molliq.2015.12.015.

Kim, H., H. Lee, T. Lim, and S. H. Ahn. 2018. "Facile fabrication of porous Sn-based catalysts for electrochemical $\mathrm{CO}_{2}$ reduction to $\mathrm{HCOOH}$ and syngas". Journal of Industrial and Engineering Chemistry 66 (october): 248-53. https://doi.org/10.1016/j.jiec.2018.05.036.

Lai, Q., N. Yang, and G. Q. Yuan. 2017. "Highly efficient In-Sn alloy catalysts for electrochemical reduction of $\mathrm{CO}_{2}$ to formate". Electrochemistry Communications 83 (october): 24-27. https://doi.org/10.1016/j.elecom.2017.08.015.

Lee, C.-L., D.-H. Nam, J.-Y. Eom, and H.-S. Kwon. 2016. "Fabrication of tin-cobalt/carbon composite electrodes by electrodeposition using cationic surfactant for lithium-ion batteries". Electronic Materials Letters 12, no. 5 (september): 622-27. https://doi.org/10.1007/s13391-016-6077-2.

Lee, Y. R., and K. H. Row. 2016. "Comparison of ionic liquids and deep eutectic solvents as additives for the ultrasonic extraction of astaxanthin from marine plants". Journal of Industrial and Engineering Chemistry 39 (july): 87-92. https://doi.org/10.1016/j.jiec.2016.05.014.

Liu, C., C. Li, W. Wang, M. Ozkan, and C. S. Ozkan. 2017. "Facile synthesis of nickel nanofoam architectures for applications in Li-ion batteries". Energy Technology 5, no. 3 (march): 42227. https://doi.org/10.1002/ente.201600306.

Liu, J., B. Campbell, R. Ye, J. Bell, Z. Mutlu, C. Li, Y. Yan, M. Ozkan, and C. Ozkan. 2017. "Facile and scalable synthesis of copolymer-sulfur composites as cathodes for high performance 
lithium-sulfur batteries". MRS Advances 2, no. 54: 3271-76. https://doi.org/10.1557/adv.2017.444.

López-León, S., R. Ortega-Borges, and G. Brisard. 2013. "Nickel electrodeposition from protic ionic liquids based on carboxylate anions as electrolyte: II. Electrodeposition from 2hydroxyethyl ammonium propionate". International Journal of Electrochemical Science 8, no. 1 (january): 1382-93.

Malaquias, J. C., M. Steichen, and P. J. Dale. 2015. "One-step electrodeposition of metal precursors from a deep eutectic solvent for $\mathrm{Cu}(\mathrm{In}, \mathrm{Ga}) \mathrm{Se}_{2}$ thin film solar cells". $\begin{array}{lllll}\text { Electrochimica } & \text { Acta } & 151 & \text { (january): }\end{array}$ https://doi.org/10.1016/j.electacta.2014.11.089.

Martis, P., V. S. Dilimon, J. Delhalle, and Z. Mekhalif. 2011. "Impact of surface functionalization of MWCNTs on electrogenerated Ni/MWCNT composites from aqueous solutions". Materials Chemistry and Physics 128, no. 1-2 (july): 133-40. https://doi.org/10.1016/j.matchemphys.2011.02.048.

Meinshausen, L., S. Bhassyvasantha, B. S. Majumdar, and I. Dutta. 2016. "Influence of indium addition on whisker mitigation in electroplated tin coatings on copper substrates". Journal of Electronic Materials 45, no. 1: 791-801. https://doi.org/10.1007/s11664-015-4204-8.

Molenda, J., and M. Molenda. 2011. "Composite cathode material for Li-ion batteries based on $\mathrm{LiFePO}_{4}$ system". In Metal, ceramic and polymeric composites for various uses, edited by J. Cuppoletti, 621-36. IntechOpen. https://doi.org/10.5772/21635.

Monnens, W., C. Deferm, J. Sniekers, J. Fransaer, and K. Binnemans. 2019. "Electrodeposition of indium from non-aqueous electrolytes". Chemical Communications 55, no. 33: 4789-92. https://doi.org/10.1039/c8cc10254f.

Mukaibo, H., T. Momma, and T. Osaka. 2005. "Changes of electro-deposited Sn-Ni alloy thin film for lithium ion battery anodes during charge discharge cycling". Journal of Power Sources 146, no. 1-2 (august): 457-63. https://doi.org/10.1016/j.jpowsour.2005.03.043.

Naille, S., C. M. Ionica-Bousquet, F. Robert, F. Morato, P.-E. Lippens, and J. Olivier-Fourcade. 2007. "Sn-based intermetallic materials. Performances and mechanisms". Journal of Power Sources 174, no. 2 (december): 1091-94. https://doi.org/10.1016/j.jpowsour.2007.06.040.

Nam, D. H., R. H. Kim, D. W. Han, and H. S. Kwon. 2012. "Electrochemical performances of Sn anode electrodeposited on porous $\mathrm{Cu}$ foam for Li-Ion batteries". Electrochimica Acta 66 (april): 126-32. https://doi.org/10.1016/j.electacta.2012.01.084.

Pereira, N. M., O. Brincoveanu, A. G. Pantazi, C. M. Pereira, J. P. Araújo, A. F. Silva, M. Enachescu, and L. Anicai. 2017. "Electrodeposition of Co and Co composites with carbon nanotubes using choline chloride-based ionic liquids". Surface \& Coatings Technology 324 (september): 451-62. https://doi.org/10.1016/j.surfcoat.2017.06.002.

Pereira, N. M., S. Salomé, C. M. Pereira, and A. F. Silva. 2012. "Zn-Sn electrodeposition from deep eutectic solvents containing EDTA, HEDTA, and Idranal VII". Journal of Applied Electrochemistry 42, no. 8 (august): 561-71. https://doi.org/10.1007/s10800-012-0431-3.

Piercy, R., and N. A. Hampson. 1975. "The electrochemistry of indium". Journal of Applied Electrochemistry 5, no. 1 (february): 1-15. https://doi.org/10.1007/bf00625955.

Polat, B. D., A. Abouimrane, N. Sezgin, O. Keles, and K. Amine. 2014. "Use of multilayered Ni$\mathrm{Sn}$ and Ni-Sn-C thin film anodes for lithium-ion batteries". Electrochimica Acta 135 (july): 585-93. https://doi.org/10.1016/j.electacta.2014.05.024. 
Praveen, B. M., and T. V. Venkatesha. 2009. "Electrodeposition and properties of Zn-Ni-CNT composite coatings". Journal of Alloys and Compounds 482, no. 1-2 (august): 53-57. https://doi.org/10.1016/j.jallcom.2009.04.056.

Rashad, M., F. Pan, M. Asif, and L. Li. 2015. "Enhanced ductility of Mg-3Al-1Zn alloy reinforced with short length multi-walled carbon nanotubes using a powder metallurgy method". Progress in Natural Science: Materials International 25, no. 4 (august): 276-81. https://doi.org/10.1016/j.pnsc.2015.08.002.

Rosoiu, S. P., A. G. Pantazi, A. Petica, A. Cojocaru, S. Costovici, C. Zanella, T. Visan, L. Anicai, and M. Enachescu. 2019. "Comparative study of Ni-Sn alloys electrodeposited from choline chloride-based ionic liquids in direct and pulsed current". Coatings 9, no. 12: Article number 801. https://doi.org/10.3390/coatings9120801.

Schlesinger, M. E., M. J. King, K. C. Sole, and W. G. Davenport. 2011a. "Electrolytic refining". In Extractive metallurgy of copper, 251-80. Oxford: Elsevier. https://doi.org/10.1016/B978-008-096789-9.10014-9.

- - . 2011b. "Electrowinning". In Extractive metallurgy of copper, 349-72. Oxford: Elsevier. https://doi.org/10.1016/B978-0-08-096789-9.10017-4.

Schwarz-Schampera, U., and P. M. Herzig. 2002. Indium: Geology, mineralogy, and economics. Springer-Verlag. https://doi.org/10.1007/978-3-662-05076-7.

Shafiei, M., and A. T. Alpas. 2011. "Electrochemical performance of a tin-coated carbon fibre electrode for rechargeable lithium-ion batteries". Journal of Power Sources 196, no. 18 (september): 7771-78. https://doi.org/10.1016/j.jpowsour.2011.04.053.

Shi, P., X.-Q. Zhang, X. Shen, R. Zhang, H. Liu, and Q. Zhang. 2020. "A review of composite lithium metal anode for practical applications". Advanced Materials Technologies 5, no. 1 (january): Article number 1900806. https://doi.org/10.1002/admt.201900806.

Shin, H. C., and M. Liu. 2005. "Three-dimensional porous copper-tin alloy electrodes for rechargeable lithium batteries". Advanced Functional Materials 15, no. 4 (april): 582-86. https://doi.org/10.1002/adfm.200305165.

Smith, E. L., A. P. Abbott, and K. S. Ryder. 2014. "Deep eutectic solvents (DESs) and their applications". Chemical Reviews 114, no. 21 (november): 11060-82. https://doi.org/10.1021/cr300162p.

Sobha Jayakrishnan, D. 2012. "Electrodeposition: The versatile technique for nanomaterials". In Corrosion protection and control using nanomaterials, edited by V. S. Saji and R. Cook, 86-125. Woodhead Publishing. https://doi.org/10.1533/9780857095800.1.86.

Subramanian, B., S. Mohan, and S. Jayakrishnan. 2007. "Selective area deposition of Tin-Nickel alloy coating - An alternative for decorative chromium plating". Journal of Applied Electrochemistry 37, no. 2 (february): 219-24. https://doi.org/10.1007/s10800-006-92366.

Tarascon, J.-M., and M. Armand. 2001. "Issues and challenges facing rechargeable lithium batteries". Nature 414, no. 6861 (november): 359-67. https://doi.org/10.1038/35104644.

Tarditi, A. M., M. L. Bosko, and L. M. Cornaglia. 2017. "Electroless plating of Pd binary and ternary alloys and surface characteristics for application in hydrogen separation". In Comprehensive materials finishing, 1-24. Oxford: Elsevier. https://doi.org/10.1016/B9780-12-803581-8.09166-9. 
Tocoglu, U., O. Cevher, M. O. Guler, and H. Akbulut. 2014. "Core-shell tin-multi walled carbon nanotube composite anodes for lithium ion batteries". International Journal of Hydrogen Energy 39, no. 36 (december): 21386-90. https://doi.org/10.1016/j.ijhydene.2014.05.053.

Uysal, M., H. Gul, A. Alp, and H. Akbulut. 2014. "Sn-Ni/MWCNT nanocomposite negative electrodes for Li-ion batteries: The effect of $\mathrm{Sn}: \mathrm{Ni}$ molar ratio". International Journal of Hydrogen Energy 39, no. 36 (december): 21391-98. https://doi.org/10.1016/j.ijhydene.2014.01.099.

Walsh, F. C., and D. R. Gabe. 1979. "The electrodeposition of indium". Surface Technology 8, no. 2 (february): 87-99. https://doi.org/10.1016/0376-4583(79)90054-2.

Walsh, F. C., and C. T. J. Low. 2016a. "A review of developments in the electrodeposition of tin-copper alloys". Surface and Coatings Technology 304 (october): 246-62. https://doi.org/10.1016/j.surfcoat.2016.06.065.

- - - 2016b. "A review of developments in the electrodeposition of tin". Surface and $\begin{array}{llll}\text { Coatings } & \text { Technology } & 288 & \text { (february): }\end{array}$ https://doi.org/10.1016/j.surfcoat.2015.12.081.

Wang, G., B. Wang, X. Wang, J. Park, S. Dou, H. Ahn, and K. Kim. 2009. "Sn/graphene nanocomposite with 3D architecture for enhanced reversible lithium storage in lithium ion batteries". Journal of Materials Chemistry 19, no. 44: 8378-84. https://doi.org/10.1039/b914650d.

Wang, G. X., J.-H. Ahn, M. J. Lindsay, L. Sun, D. H. Bradhurst, S. X. Dou, and H. K. Liu. 2001. "Graphite-Tin composites as anode materials for lithium-ion batteries". Journal of Power Sources 97-98 (july): 211-15. https://doi.org/10.1016/s0378-7753(01)00619-x.

Xia, Z. P., Y. Lin, and Z. Q. Li. 2008. "A new phase in Ni-Sn-P system and its property as an anode material for lithium-ion batteries". Materials Characterization 59, no. 9 (september): 132428. https://doi.org/10.1016/j.matchar.2007.11.004.

Xu, Y., Q. Liu, Y. Zhu, Y. Liu, A. Langrock, M. R. Zachariah, and C. Wang. 2013a. "Uniform nano$\mathrm{Sn} / \mathrm{C}$ composite anodes for lithium ion batteries". Nano Letters 13, no. 2 (february): 47074. https://doi.org/10.1021/nl303823k.

Xu, Y., Y. Zhu, Y. Liu, and C. Wang. 2013b. "Electrochemical performance of porous carbon/tin composite anodes for sodium-ion and lithium-ion batteries". Advanced Energy Materials 3, no. 1 (january): 128-33. https://doi.org/10.1002/aenm.201200346.

Zein El Abedin, S., A. Y. Saad, H. K. Farag, N. Borisenko, Q. X. Liu, and F. Endres. 2007. "Electrodeposition of selenium, indium and copper in an air- and water-stable ionic liquid at variable temperatures". Electrochimica Acta 52, no. 8 (february): 2746-54. https://doi.org/10.1016/j.electacta.2006.08.064.

Zhang, J. X. J., and K. Hoshino. 2014. "Fundamentals of nano/microfabrication and effect of scaling". In Molecular sensors and nanodevices: Principles, designs and applications in biomedical engineering, 43-101. Oxford: William Andrew Publishing. https://doi.org/10.1016/B978-1-4557-7631-3.00002-8.

Zhao, J., P. Liu, Z. Yang, P. Zhou, and Y. Zhang. 2011. "One-step cutting of multi-walled carbon nanotubes using nanoscissors". Nano-Micro Letters 3, no. 2: 86-90. https://doi.org/10.1007/bf03353656.

Zhu, X., Y. Zhu, S. Murali, M. D. Stoller, and R. S. Ruoff. 2011. "Reduced graphene oxide/tin oxide composite as an enhanced anode material for lithium ion batteries prepared by homogenous coprecipitation". Journal of Power Sources 196, no. 15 (august): 6473-77. https://doi.org/10.1016/j.jpowsour.2011.04.015. 
Zuo, S., D. Li, Z. Wu, Y. Sun, Q. Lu, F. Wang, R. Zhuo, D. Yan, J. Wang, and P. Yan. 2018. " $\mathrm{SnO}_{2}$ /graphene oxide composite material with high rate performance applied in lithium storage capacity". Electrochimica Acta 264 (february): 61-68. https://doi.org/10.1016/j.electacta.2018.01.093.

\section{Acknowledgments}

This work was carried out with financial support from FCT under Research Grant QUI/UI0081/2019 - CIQUP and IL4Energy project (02/SAICT/2017) funded by FCT and the European Funds for regional development (FEDER) through the operational program of competitiveness and internationalization with reference POCI-01-0145-FEDER-032294.

The authors would like to thank the COST Action CA15107 - MULTICOMP (MULTIFUNCTIONAL NANO-CARBON COMPOSITE MATERIALS NETWORK).

Ana Brandão would like to thank SCANSCI - equipamentos de laboratório for the financial support given to the Ph.D. program and ILs4Energy project for the research grant. 